\title{
Investigation of Physical and Numerical Model of Archimedes Screw Turbine
}

\author{
Omar Sulaiman Abdullah'1, Wissam Hashim Khalil'2, Ammar Hatem Kamel'1, Amir J. Shareef ${ }^{2}$ \\ ${ }^{1}$ Dams \& Water Resources Engineering Department, Engineering College, University of Anbar, Ramadi, Iraq \\ ${ }^{2}$ Renewable Energy Research Center, University of Anbar, Ramadi, Iraq \\ Email: wissam.gmw@uoanbar.edu.iq,eng.ajsh2006@uoanbar.edu.iq
}

How to cite this paper: Abdullah, O.S. Khalil, W.H., Kamel, A.H. and Shareef, A.J. (2020) Investigation of Physical and $\mathrm{Nu}$ merical Model of Archimedes Screw Turbine. Journal of Power and Energy Engineering, 8, 26-42.

https://doi.org/10.4236/jpee.2020.810003

Received: September 3, 2020

Accepted: October 20, 2020

Published: October 23, 2020

Copyright $\odot 2020$ by author(s) and Scientific Research Publishing Inc. This work is licensed under the Creative Commons Attribution International License (CC BY 4.0).

http://creativecommons.org/licenses/by/4.0/

\begin{abstract}
Archimedes screw turbines have been developed as they work with a low head with high efficiency, where flow energy can be exploited in small rivers, streams, regulators and others. The power can be produced using Archimedes turbines and depends on some parameters including the number of blades, flow, and angle of the shaft inclination and the length of the pitch. A physical and numerical model has been developed to determine the performance of the Archimedes turbine on the Ramadi Dam in Iraq. The physical model was made of stainless steel with the following parameters (length $1000 \mathrm{~mm}$, pitch $70 \mathrm{~mm}$, diameter ratio 0.536 , inclination angles $30^{\circ}, 35^{\circ}, 40^{\circ}, 45^{\circ}$ ). Work was carried out on different flow rates and inclination angles. The experimental results showed that the highest efficiency was $81.4 \%$ at $35^{\circ}$ inclination angle and a flow rate of $1.12 \mathrm{l} / \mathrm{s}$; the maximum power of 9.03 watts was at a $45^{\circ}$ inclination angle and a flow rate of $2.065 \mathrm{l} / \mathrm{s}$ and $72 \%$ efficiency. Also, the impact of the pitch and the number of blades were studied. The results show that torque is increase with an increase in the pitch length, and torque is decreased with increase in several blades. The numerical results showed that the using of two blades led to a greater power produced. The comparison of the numerical and experimental results showed a good agreement, also the comparison with the published data showed a good agreement. As a final result the Archimedes screw has many positive points making it a good potential candidate. The results that emerged show the possibility of using this type of turbine in the Euphrates River in Anbar Governorate-Iraq, as the province is characterized by the presence of many regulators on the river in which turbines can be employed.
\end{abstract}

\section{Keywords}

Archimedes Screw Turbine, Physical Model, Small Hydropower Station, CFD, Low Head Turbine 


\section{Introduction}

At present, one of the most important challenges facing the world in the production of sustainable energy for several reasons, includes decreasing fossil fuels, increasing pollution and increasing carbon dioxide emissions. Therefore, researchers are advised to use clean and renewable alternative energies such as wind energy, hydropower, solar energy and geothermal energy as in [1].

In recent years, Iraq has begun to suffer from a problem in generating electricity due to the low level of water levels in dams, which has disrupted the work of turbines, including the Haditha dam in Anbar province. Water levels within the Tigris and Euphrates rivers are expected to drop by $25 \%, 50 \%$, respectively according to [2]. So one of the solutions is to use small-scale power plants.

Hydropower is one of the most important sources of electricity generation where the total percentage of energy around the world is estimated at $20 \%$ that comes from hydropower plants; in some countries the ratio of energy is generated by chromium energy to $80 \%$ as shown in [3].

Archimedes screw turbines have been used to exploit hydropower sources such as irrigation canals, streams, etc. to solve the power crisis.

Archimedes screw is a hydraulic machine considered one of the oldest machines where it was used as a pump to raise water from low to high places, and this machine is attributed to Archimedes (287-212 B.C) [4].

Currently, Archimedes screw turbines have begun to spread wider in low-head areas of Europe due to their high efficiency of up to $80 \%$ and lack of environmental impact, and one of the most important features is that it works with a low head less than $5 \mathrm{~m}[5]$.

There is an important feature of the Archimedes screw that is different from other techniques which is that it is a friend of the fish where it allows the fish to pass through it without any effect on it [6].

Reference [7] mentioned that the first to use the Archimedes screw to generate energy instead of a pump to raise water is Brada (1999).

In recent years a wave of practical and theoretical studies has been conducted by researchers to obtain optimal specifications and dimensions of the Archimedes turbine to improve its performance among them 2000 where he presented an analytical study for the development of the performance of a screw for the Shrimps and determine the dimensions and the optimum geometry of the screw where he specified ratios of the female teachers of which the percentage of the radius depends on the number of blades [8].

The geometric shape of Archimedes, as well as flow losses, has a great impact on the efficiency of the screw according to the analytical model presented by taking into account the losses of water due to the Gap between the screw and the casing (Trough) [9].

Reference [10] presented a study on the performance of the Archimedes turbine, which found that the energy increases by increasing the angle of inclination. 
Another study [11] of the effect of angle of inclination (Müller and Senior 2009), they find that efficiency increases with the increase in the number of laps and decreases the angle of inclination for the screw and that efficiency depends on the geometric dimensions of the shape and the losses.

Reference [12] presented an empirical and numerical study to find out the performance of the Archimedes turbine. The numerical study was using CFD. The test was conducted at different flow rates, where efficiency was higher than $80 \%$, and there was also compatibility between numerical and experimental results. The increasing consumption of electric energy and significant storage of natural resources has created an urgent need for more studies on alternative sources of energy. The sustainability of natural resources makes researchers facing great challenges to make the most benefit of these resources.

Reference [13] studied the effect of Froude number on the performance of Archimedes screw turbine as its application of free surface flow. The results of this study proved that the increasing of Froude number lead to create vortices which decreases the efficiency of such turbines. Reference [14] proved in their experiments that the Archimedes Screw turbine has a low environmental effect and its efficient mean for generating power at low head sites. Also they recommend such turbine for using in rural area. Reference [15] and [16] performed a 3-D model for the effect of number of blades on the performance of Archimedes screw turbine. Their analyses proved that the performance of such turbines is very affected by the number of blades. Also their simulations present the fact that the using of two blades gave higher stability in the performance of such turbines. The extraction of potential energy from small rivers or irrigation canals was studied experimentally by [17]. The experiments of the screw turbine have shown good potential to be used for low head micro hydro-electrical plants. Reference [18] investigated the performance of Archimedes screw turbines to determine the main parameters that affect its performance. Tests were performed at variant flowrate. The results obtained from this investigation indicate that to attain higher efficiency the flowrate should be as high as possible.

The current research aims to reduce the gap in previous studies. Also, this study tries to find the most important factors affecting the performance of this type of turbine in order to increase its efficiency and productivity. The study includes carrying out an experimental rig design and completing practical tests on it. After completing the mentioned practical part, using computational fluid dynamics to simulate the manufactured test turbine and conducting an extensive study on it and make a comparison between the two parts. Comparing these two concepts will give a clear perception of the factors affecting the performance of Archimedes turbine and how to improve it.

\section{Experimental Model}

The physical model is made from locally available materials where this reduces the cost of manufacturing. Archimedes turbine consists of a hollow shaft made of stainless steel, helixes (as shown in Figure 1) are discs that have been cut and 


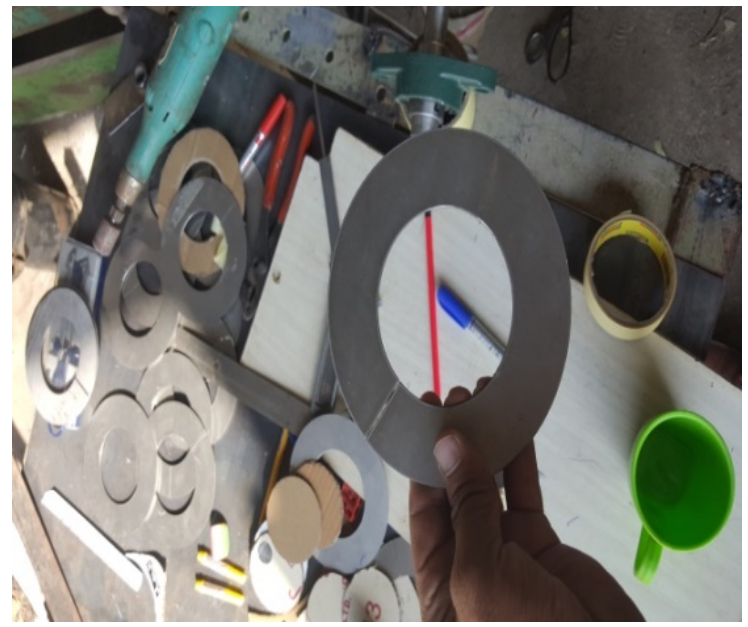

Figure 1. The helix before welded on shaft.

then welded over the shaft. After the blade welding on the shaft, the screw and is surrounded by a casing called trough. The trough is a pipe of mild iron, part of it was cut and removed from the top of the pipe. The screw is placed inside the trough and separated by a distance called Gap which is necessary to facilitate the movement of the screw inside the trough. The Performance of the screw turbine will be affected by the angle of inclination. Hence the screw inclination can be controlled to study its effect in the experiments. All dimensions of the experimental setup are listed as shown in Table 1 (Figure 2).

\subsection{Open Channel}

To secure the amount of water needed for practical experiments, and open channel in the hydraulic laboratory-College of Engineering (University of Anbar) shown in Figure 3 with following dimensions $17 \mathrm{~m}$ long, $0.5 \mathrm{~m}$ wide and $0.5 \mathrm{~m}$ deep. This channel equipped with water by a pump of $10 \mathrm{hp}$. Archimedes' screw was installed on the channel, to perform the experiments. Figure 4 presents the schematic diagram of the experimental set-up.

\subsection{Principals of Characteristics of Turbines}

The water power available due to the difference of the head and can be mechanically extracted using the power adapter which is the turbine. The mechanical power generated by the turbine can be converted to electrical power by electrical generators. The characteristics of the Archimedes screw turbine will be estimated depending on the following analysis on reference [19]. The hydraulic power that be supplied by the water is given below:

$$
P_{\text {hyd }}=\rho g Q H
$$

where:

$P_{\text {hyd }}:$ represent the power supplied by the water.

$\rho$ is water density, $g$ is gravitation acceleration, $Q$ is the flow rate, $H$ is the head from top to end of the blade. 
Table 1. Parameters of the screw turbine experimental model.

\begin{tabular}{ccc}
\hline Parameters & Symbol & Value \\
\hline Screw length & $L$ & $1000 \mathrm{~mm}$ \\
Number of blades & $N$ & 1 \\
Inlet diameter & $D i$ & $70 \mathrm{~mm}$ \\
Outer diameter & $D o$ & $130 \mathrm{~mm}$ \\
Number of helix & $m$ & 12 \\
Pitch & $P$ & $70 \mathrm{~mm}$ \\
Trough diameter & $D t$ & $134 \mathrm{~mm}$ \\
Gap width & $G w$ & $2 \mathrm{~mm}$ \\
Slope & $\alpha$ & $30,35,40,45$ \\
\hline
\end{tabular}

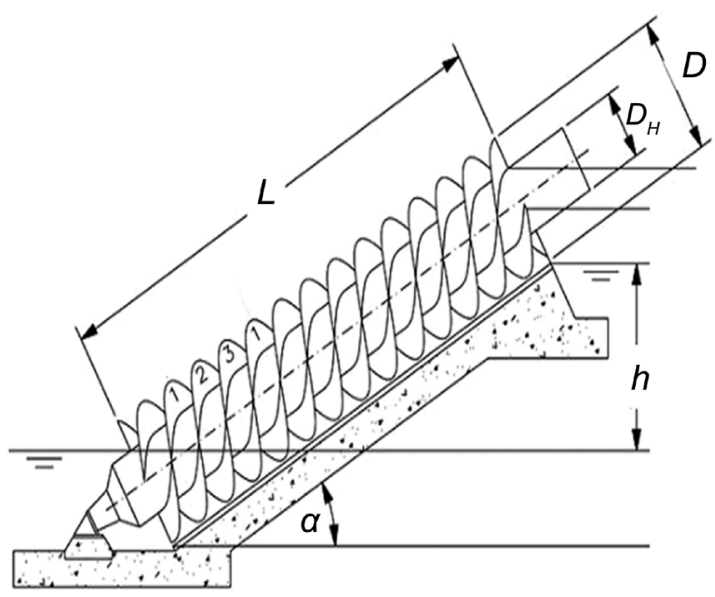

Figure 2. General parameters of Archimedes screw turbine [11].
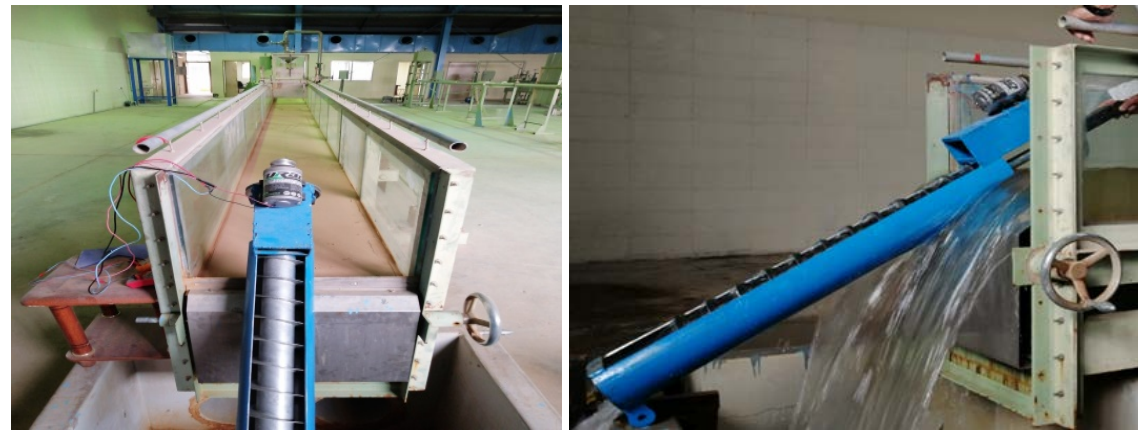

Figure 3. Experimental setup installed on open channel.

The mechanical power produced by the screw turbine $\left(P_{\text {mec }}\right)$ is estimated below:

$$
P_{\text {mec }}=T \cdot \omega
$$

where:

$T=$ represent the torque of the screw turbine and $(\omega)$, angular velocity is shown in which is computed as below: 


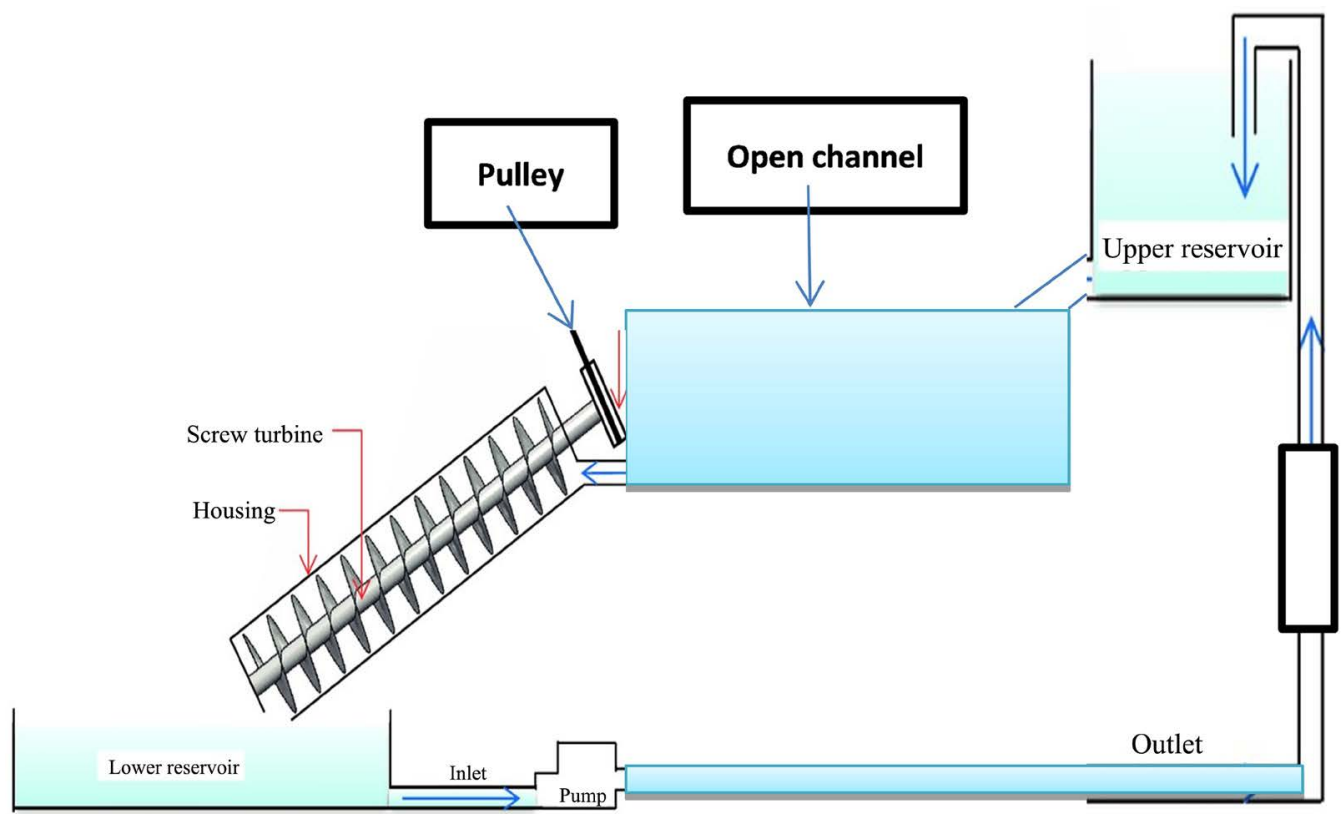

Figure 4. Schematic diagram of the experimental set-up.

$$
\omega=\frac{2 \pi n}{60}
$$

where:

$n:$ is the number of rotation per minute.

The efficiency of the screw turbine is calculated by:

$$
\eta=\frac{P_{\mathrm{mec}}}{P_{\mathrm{hyd}}} * 100 \%
$$

\subsection{Uncertainty Analysis}

An uncertainty analysis is an important tool in experimental investigations. This can be performed for the instrumentations that be used in the experimental arrangements. For each measured variable, one or more elemental uncertainties can contribute to the total uncertainties for the variable. These elemental uncertainties were combined using the Root Mean Squared (RMS) rate method according to [20] and [21]. For the measured variables in the different experiments, the results for the elemental uncertainties are summarized in Table 2 \& Table 3.

\section{Numerical Model}

Fluid dynamics is a branch of mechanical engineering that deals with fluid flow. Generally, fluid motion can be an investigated in several methods which include experimental base study, theoretical study and numerical method. The numerical approach is based on computational fluid dynamics (CFD). In this current work of the simulation of Archimedes screw turbine will be done using ANSYS FLUENT as a software. 
Table 2. The Accuracy values of equipments.

\begin{tabular}{ccc}
\hline Equipment & Resolution & Accuracy \\
\hline Ammeter & $0.01 \mathrm{Amps}$ & $\pm 1.5 \%$ \\
Voltmeter & 0.01 Volts & $\pm 2 \%$ \\
Rotameter & $0.01 \mathrm{~L} / \mathrm{s}$ & $\pm 3 \%$ \\
Tachometer & $0.5 \mathrm{rpm}$ & $\pm 2 \%$ \\
\hline
\end{tabular}

Table 3. The Accuracy values of different variable.

\begin{tabular}{cc}
\hline Parameter & Uncertainty \\
\hline Flowrate & $\pm 1.8 \mathrm{~m}^{3} / \mathrm{s}$ \\
Rotation of Speed & $\pm 2 \% \mathrm{rpm}$ \\
Torque & $\pm 3.5 \mathrm{~N} \cdot \mathrm{m}$ \\
Power & $\pm 4 \mathrm{Watt}$ \\
\hline
\end{tabular}

\subsection{Geometry}

The design of the Archimedes screw turbine was made by Solid works software with same the dimensions of experimental work with change some parameters for study number of cases. Figure 5 shows the screw turbine that constructed using solid works.

\subsection{Governing Equation}

The governing equations play an important role in the fluid flow solution, generally speaking, those equations are based on classical laws of physics. The first and important one is the conservation of mass and the second equation is based on Newton's second law or momentum conservation [22].

\section{Continuity equation}

$$
\frac{\partial \rho}{\partial t}+\frac{\partial(\rho u)}{\partial x}+\frac{\partial(\rho v)}{\partial y}+\frac{\partial(\rho w)}{\partial z}=0
$$

\section{$X$-momentum equation}

$$
\frac{\partial(\rho u)}{\partial t}+\frac{\partial\left(\rho u^{2}\right)}{\partial x}+\frac{\partial(\rho u v)}{\partial y}+\frac{\partial(\rho u w)}{\partial z}=-\frac{\partial p}{\partial x}+\frac{1}{\operatorname{Re}}\left[\frac{\partial \tau_{x x}}{\partial x}+\frac{\partial \tau_{x y}}{\partial y}+\frac{\partial \tau_{x z}}{\partial z}\right]
$$

\section{$\underline{Y \text {-momentum equation }}$}

$$
\frac{\partial(\rho v)}{\partial t}+\frac{\partial(\rho u v)}{\partial x}+\frac{\partial\left(\rho v^{2}\right)}{\partial y}+\frac{\partial(\rho v w)}{\partial z}=-\frac{\partial p}{\partial y}+\frac{1}{\operatorname{Re}}\left[\frac{\partial \tau_{x y}}{\partial x}+\frac{\partial \tau_{y y}}{\partial y}+\frac{\partial \tau_{y z}}{\partial z}\right]
$$

\section{$Z$-momentum momentum}

$$
\frac{\partial(\rho w)}{\partial t}+\frac{\partial(\rho u w)}{\partial x}+\frac{\partial(\rho v w)}{\partial y}+\frac{\partial\left(\rho w^{2}\right)}{\partial z}=-\frac{\partial p}{\partial z}+\frac{1}{\operatorname{Re}}\left[\frac{\partial \tau_{x z}}{\partial x}+\frac{\partial \tau_{y z}}{\partial y}+\frac{\partial \tau_{z z}}{\partial z}\right]
$$

where:

$u, v, w$ are the velocity components. 


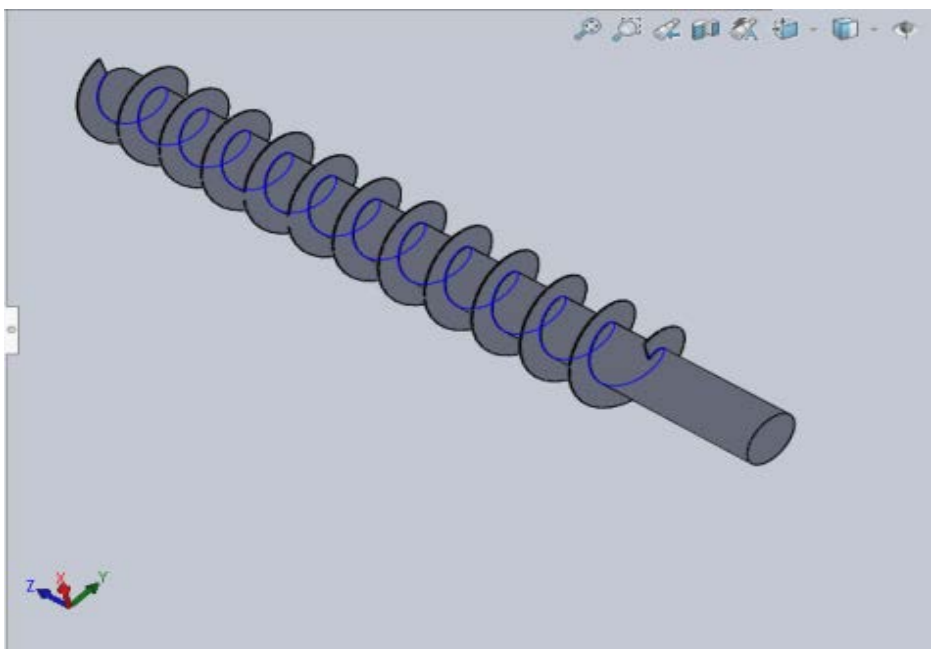

Figure 5. Screw turbine designed by Solidworks.

$x, y, z$ are the Cartesian coordinates.

$P$ : is pressure, $t$ : is the time, $\tau$ : is shear stress, and Re: is the dimensionless Reynolds number.

Turbulence phenomena modelling is a complicated task in almost all engineering fluid flow simulations to predict how turbulent fluctuations will affect the flow. Therefore, it is critical to model it as accurately as possible [23] [24].

$(k-\varepsilon)$ turbulence model is the most common model used in Computational Fluid Dynamics (CFD) to simulate mean flow characteristics for turbulent flow conditions. It is a two equation model that gives a general description of turbulence by means of two transport equations (PDEs).

\subsection{Boundary Condition}

In the numerical study, the transient flow state was used in simulation by CFD as a boundary condition. Also, the velocity of entry and pressure in an outlet and rational speed were used as a boundary condition. Some parameters are mentioned in Table 4 for both fluid and solid domains.

\subsection{Mesh Sensitivity}

After the last mention procedure, the model was sent to meshing software, it is clear that this model is quid complicated due to blades design. Therefore, it is difficult to generate a structured mesh with hexahedral shape, instead of that unstructured mesh was used. A trial and error cases were performed in the simulation without divergence due to mesh. It has been found that a tetrahedral cell size of (Minim $0.0001 \mathrm{~mm}$ and maximum $0.02 \mathrm{~mm}$ ) with the growth rate of $1: 10$, average skewness value of 0.25 and average cell quality of 0.85 , these values are considered more than acceptable and close to the perfect value that documented in the ANSYS manual. Figure 6 shows the mesh used in simulation. The building of the mesh requires a careful approach with a smaller size of mesh, this will provide greater accuracy. However, it also requires greater power consumed 
Table 4. Parameters for solid and fluid domains.

\begin{tabular}{ccc}
\hline & Water density & $998.2 \mathrm{~kg} / \mathrm{m}^{3}$ \\
Fluid Properties & Water viscosity & $(1-3) \mathrm{l} / \mathrm{s}$ \\
& Water flow rate & $0.001003 \mathrm{~kg} / \mathrm{ms}$ \\
Turbulence model & & \\
Solid domain & & \multicolumn{2}{c}{ Aluminum } \\
\hline
\end{tabular}

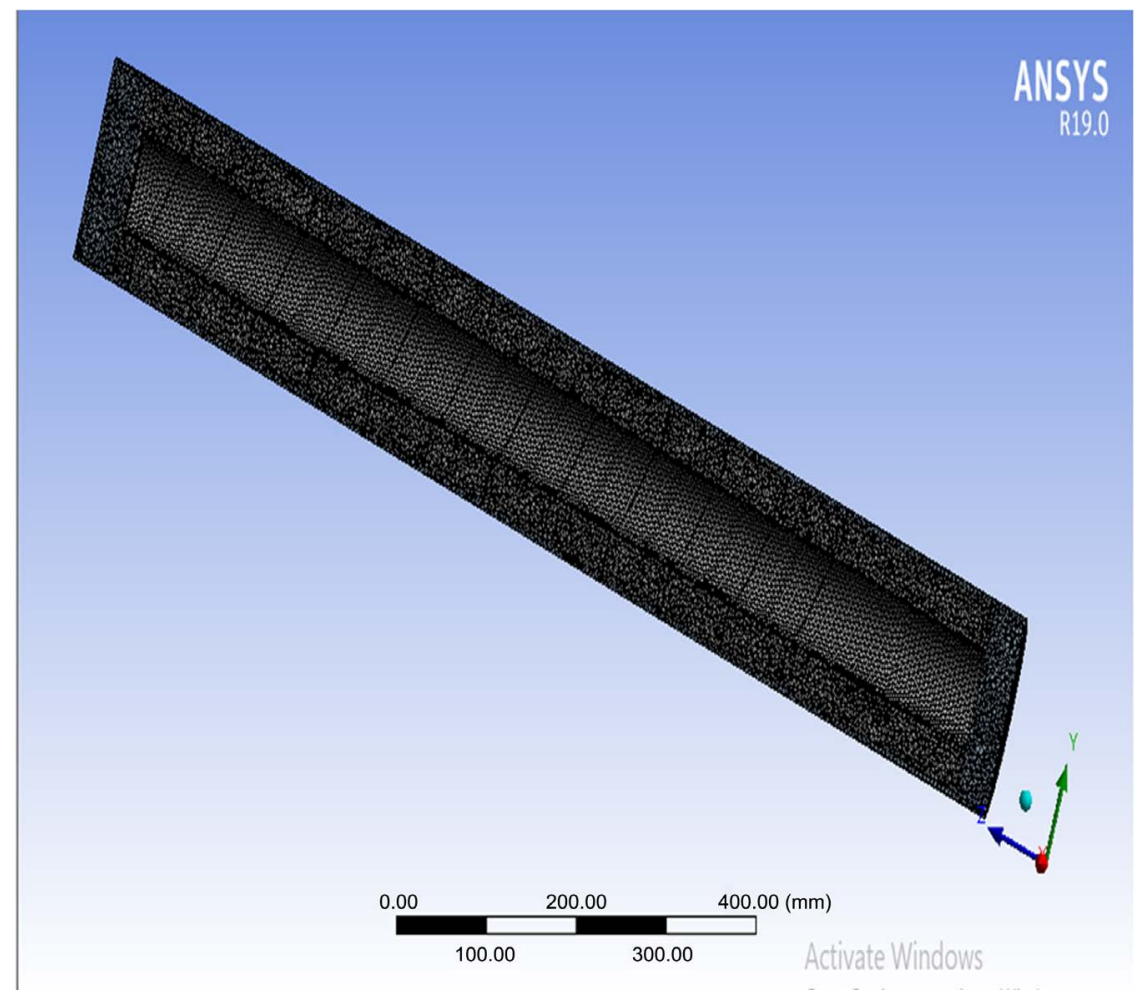

Figure 6. Mesh model of Archimedes screw turbine.

by computer and longer time to execute the runs. For this reason, it's appropriate to use a mesh size which is small enough to seize the required fluid flow phenomena accurately, without being too small that it takes uses more computational power and time than is necessary. By noting the values obtained by the solver in Figure 7, it is possible to find where the size of the mesh does not affect the output results. The variations in torque for the different mesh numbers may have been noticed in mentioned figure.

\section{Results and Discussion}

The investigation includes the studying of Archimedes screw turbine under variant conditions Figure 8 shows the relationship between flow rate and torque with an angle of inclination equal to $30^{\circ}$, it is noted from figure that the increasing of flow rate increases the torque. This is due to the increasing of the force that affects the blades, causing increasing of rotational speed and thus increased torque. 


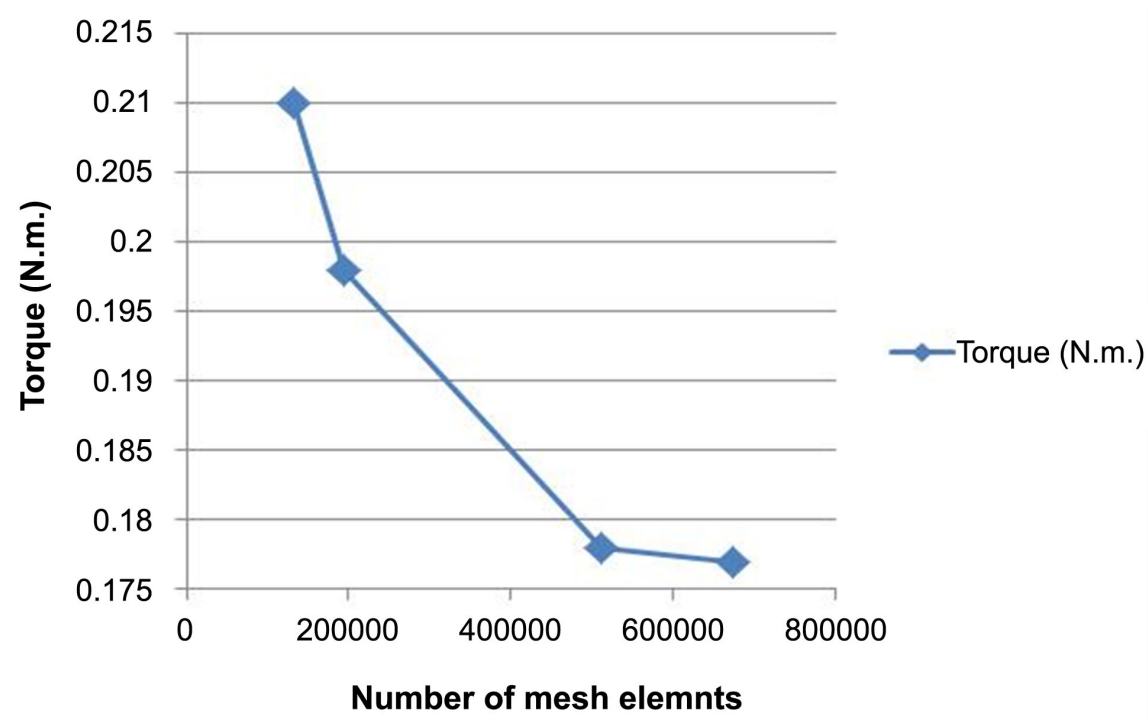

Figure 7. Number of nodes with torque (for $n=135 \mathrm{rpm}, \alpha=30^{\circ}, Q=2.97 \mathrm{l} / \mathrm{s}$ ).

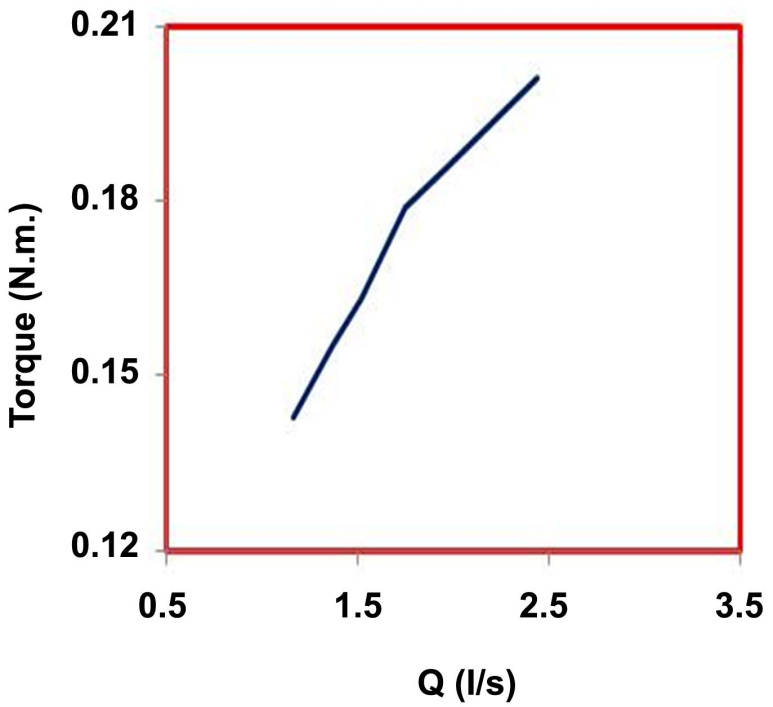

Figure 8. The relation between flow rate and torque at an angle of inclination $\left(30^{\circ}\right)$.

In terms of efficiency, it can be seen that the efficiency will increase with the increase in the flowrate until it reaches a maximum value and then begins to decrease, as shown in Figure 9. This behavior may be explained because the flow is greater than the turbine's capacity, overflow causing losses in power.

Figure 9 indicates the relation between the inclination of the screw shaft and mechanical power. It has been noted that mechanical power increase with increasing of screw inclination angle, although the losses of overflow are increase with high angles.

Numerical simulation is taken into considerations different cases. Figure 10 shows the effect of the pitch on the power produced by the turbine. There is a clear relationship between the length of the pitch and the energy produced, as the length of the pitch decreases the power produced will increase. The increase 


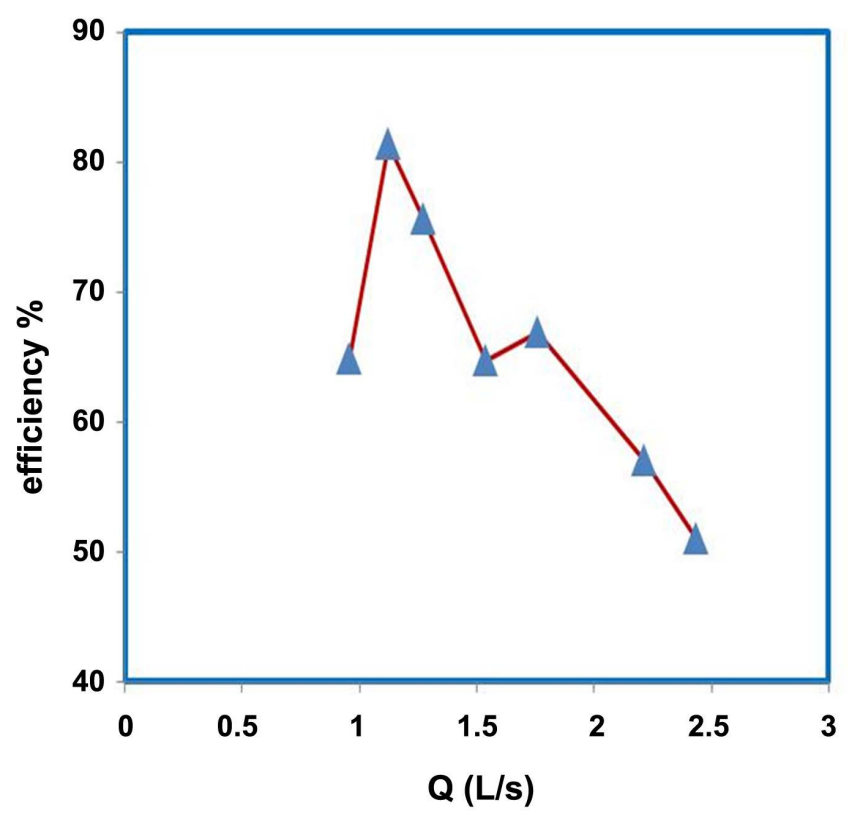

Figure 9. Flow rate with efficiency at an angle $\left(35^{\circ}\right)$.

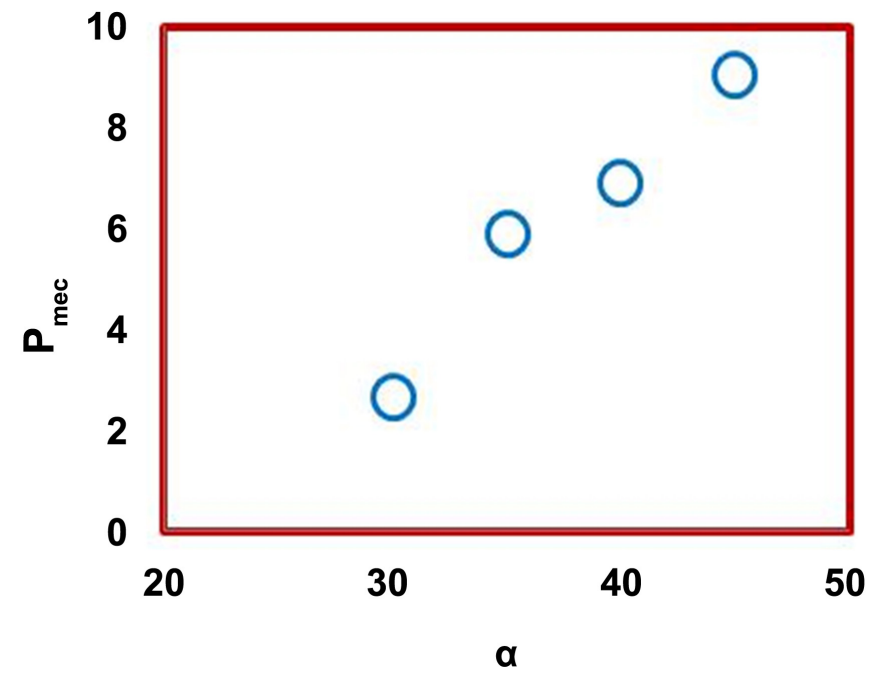

Figure 10. The relation between the inclination of the screw shaft with mechanical power with flow rate $(2.2 \mathrm{l} / \mathrm{s})$.

in the length of the pitch means a decrease in the number of buckets and at the same time decrease the surface area that comes into contact with the flowing water, and this leads to decreased torque and energy. Figure 11 presents the effect of flow-rates on power developed at different pitch. It's clear from figure that as flow-rate increase the power is increase slightly and as the pitch decreases the power increases.

Figure 12 shows the relationship between rotational speed and power at an angle of inclination of $\left(30^{\circ}\right)$ and flow rate of $1.08 \mathrm{l} / \mathrm{s}$. It can be noted that the power is increase with rotational speed and the increase continues until it reaches a point that gives the same power, despite the increase in rotational velocity, 
which means that the decrease in torque becomes greater than the increase in rotational speed.

From the numerical results, it may be noted that the increasing of number of blades lead to increasing the torque values as well as energy produced as shown in Figure 13. It is seen that the increase occurs at a different flow rate. The increase in torque may be due to the increase in surface area of the blades which is a contact area for the flowing water. It can be noted that the increase is not absolute, the figure indicate as the number of blades was three, a less torque than that of the two blades screw attained.

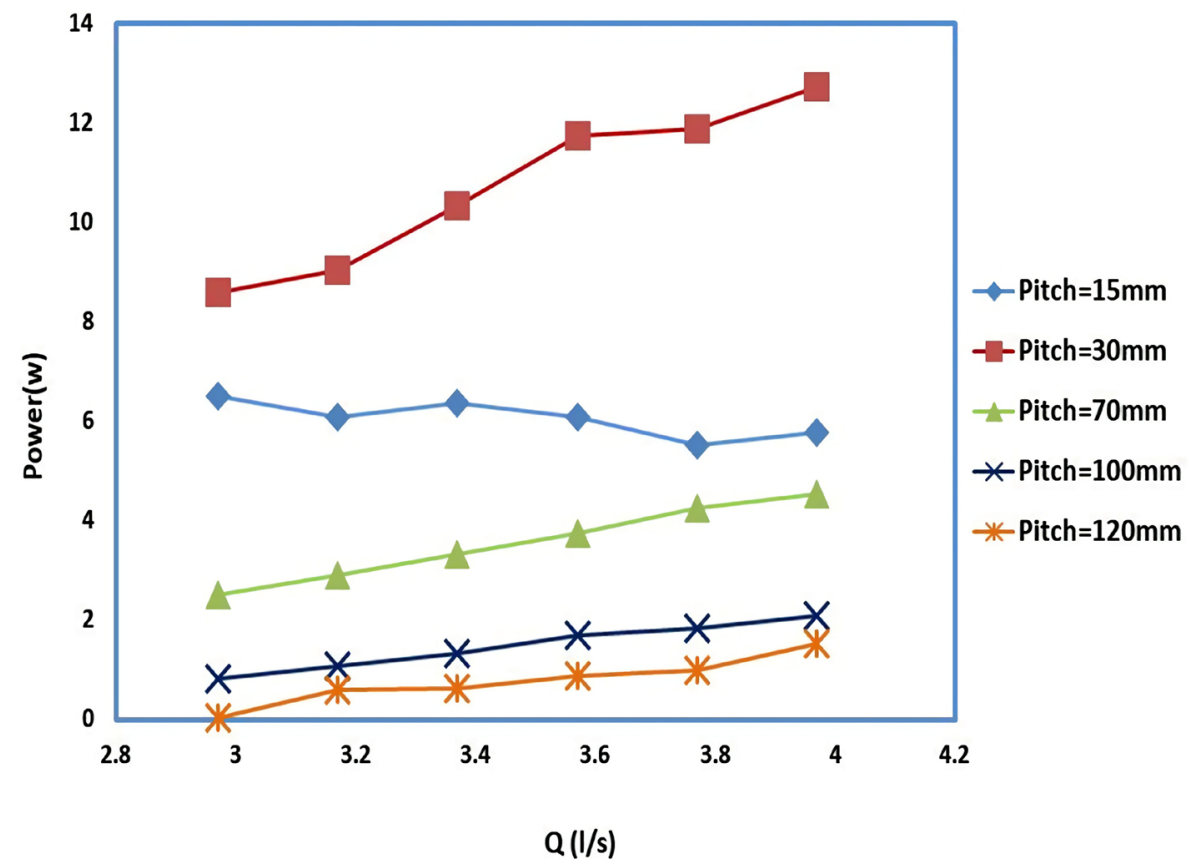

Figure 11. The relation between flow rate and torque at different pitch value.

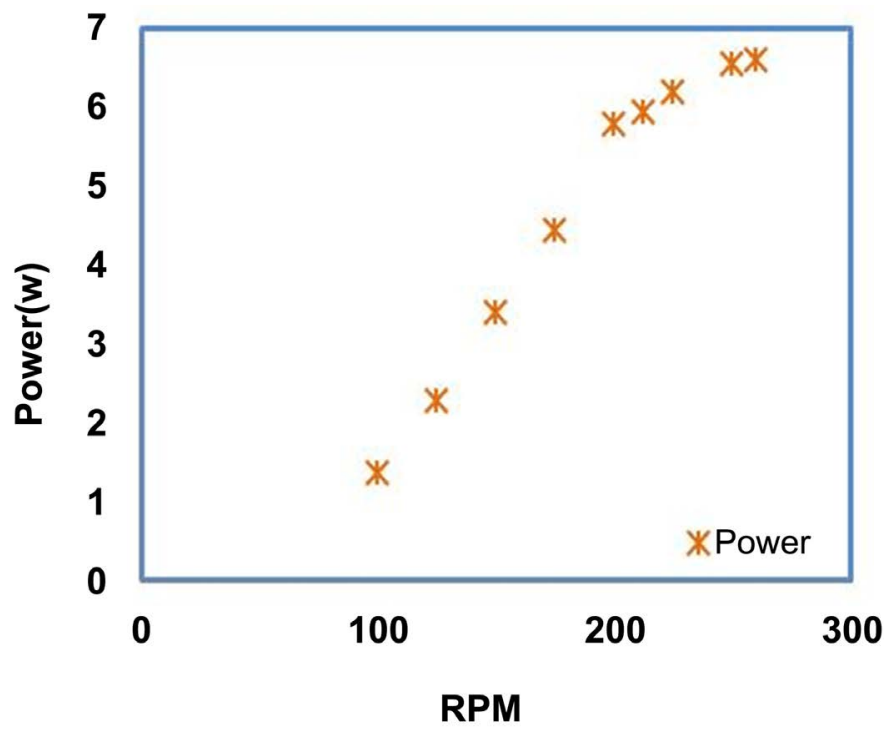

Figure 12. Power versus Rotational speed with $\left(Q=1.08 \mathrm{l} / \mathrm{s}\right.$ and $\left.30^{\circ}\right)$. 
Figure 14 shows the pressure distribution through the Archimedes screw turbine. The pressure increases in the flow direction due to hydrostatic pressure. The pressure increases with radial distance due to an increase in the dynamic pressure.

The result of velocity contour of the Archimedes turbine is shown in Figure 14.

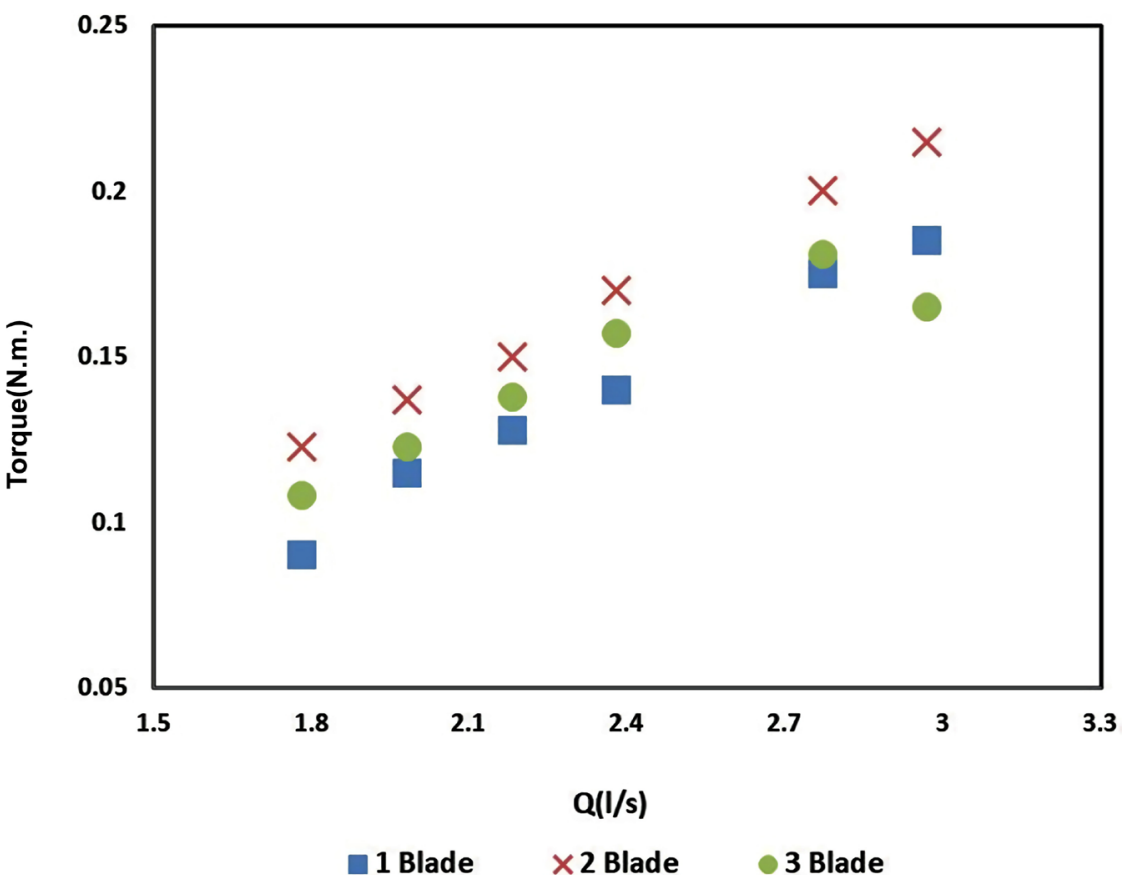

Figure 13. The relation between flow rate and torque with the number of blades.

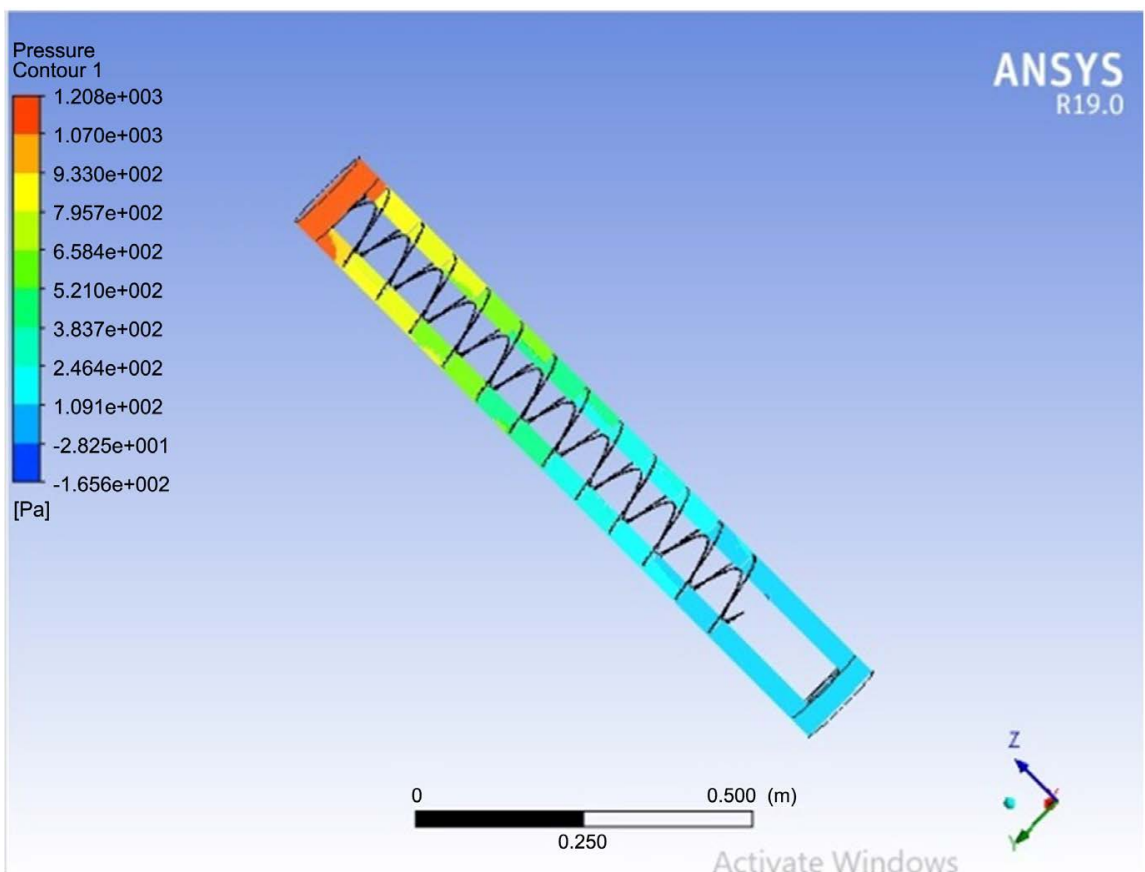

Figure 14. The pressure contour for $150 \mathrm{rpm}, 0.2 \mathrm{~m} / \mathrm{s}$ inlet velocity. 
From the figure the velocity is slow at the entrance of the turbine because of the water did not touch the screw blades. After that begins to increase as the flow of water approaches the center (Figure 15).

To verify the results produced by the numerical model, the results were compared with the results of the experimental works. Figure 16 indicated the comparison between experimental and simulation work at an angle of inclination of $\left(35^{\circ}\right)$. The figure presents the relation of the power versus the flowrate. It may be concluded from this figure that there is a very good agreement between the experimental results and numerical results. Also a comparison of the numerical results was made with that of [9]. From Figure 17 it may be indicated that the comparison has a great consistence with that published data.

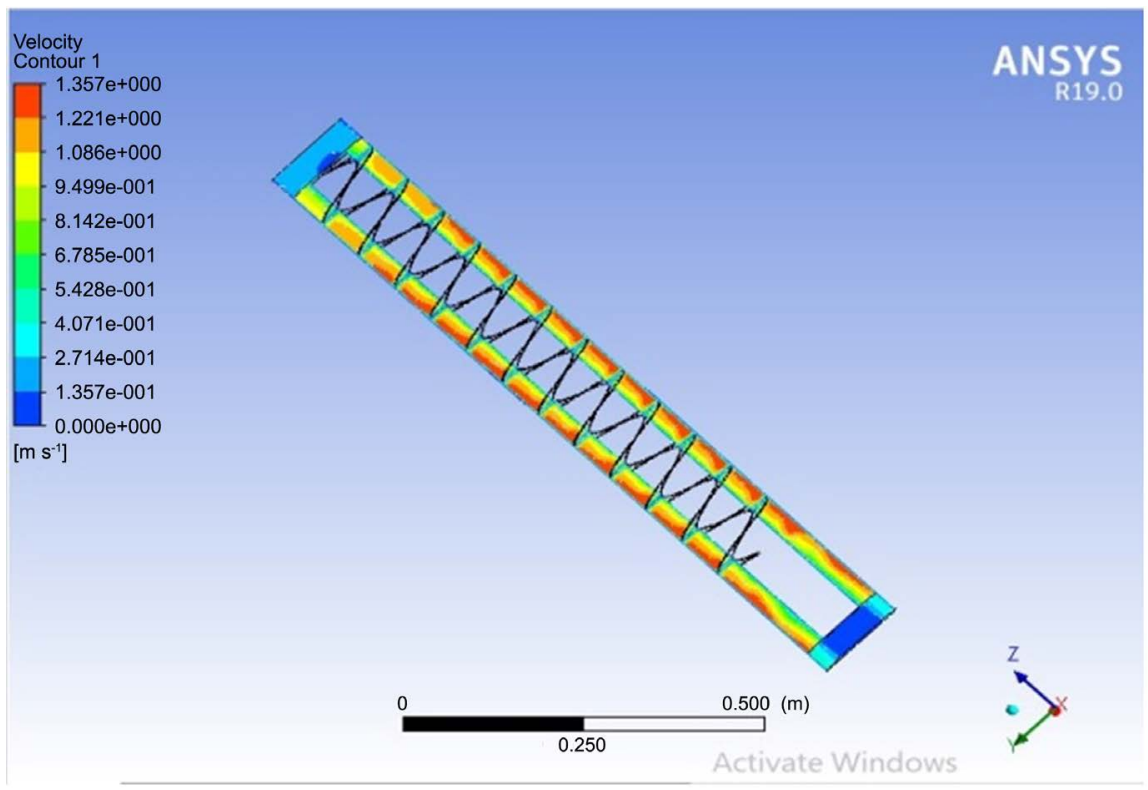

Figure 15. Velocity contour for $150 \mathrm{rpm}, 0.2 \mathrm{~m} / \mathrm{s}$.

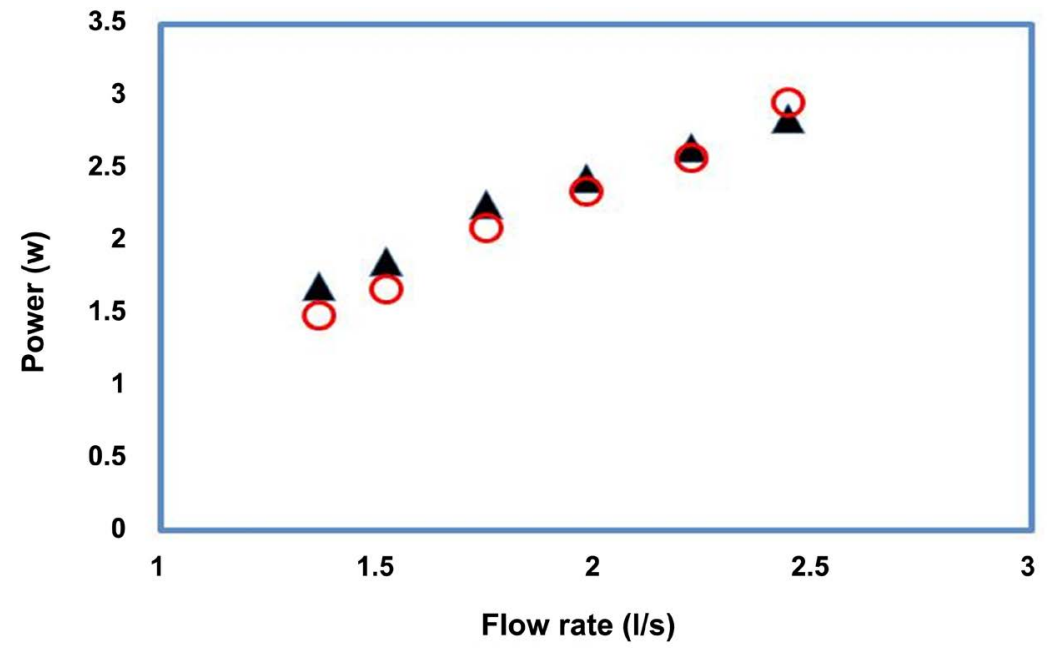

A Exp. Power OCFD. Power

Figure 16. Comparison of numerical and experimental results. 


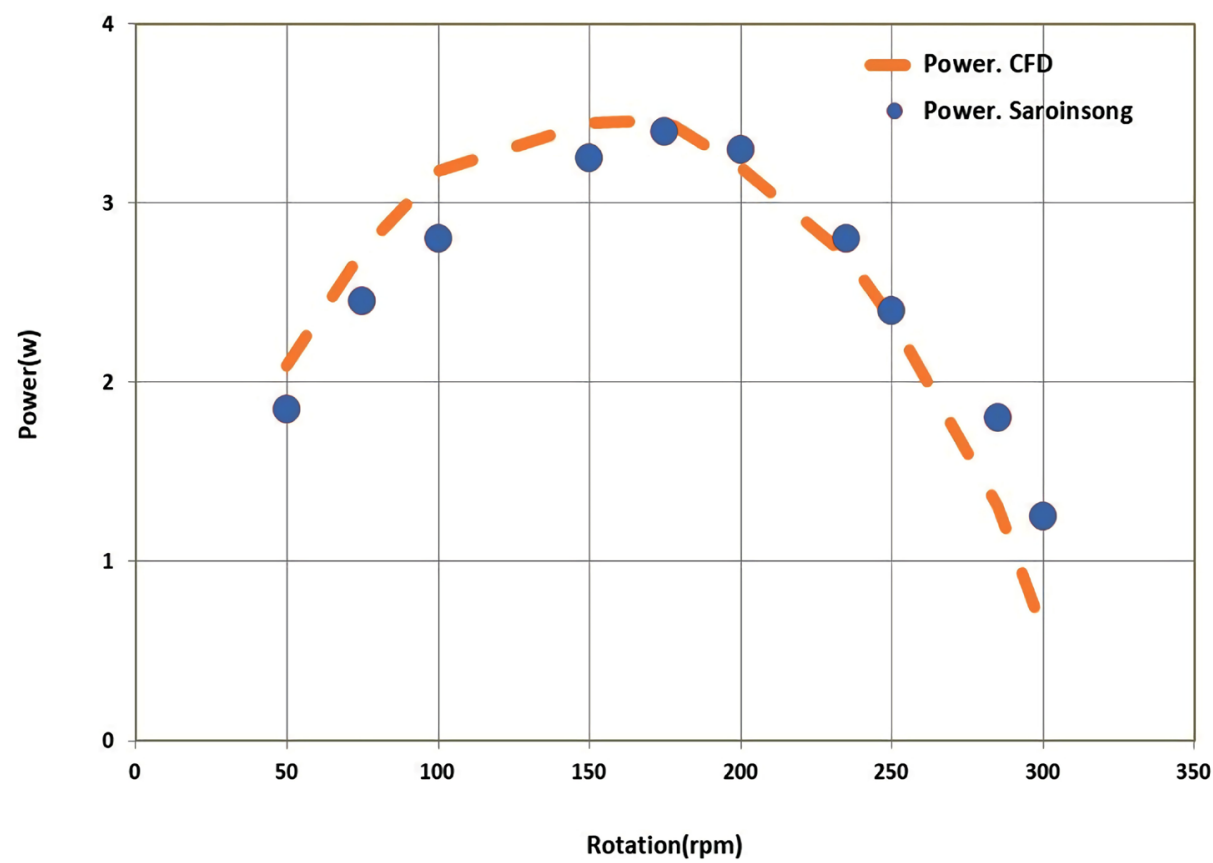

Figure 17. Comparison of numerical with previous experimental results.

\section{Conclusions}

This work studied Archimedes screw turbine with varying parameters and tested them at a set of flow rates, inclination angles and speeds in order accurately characterize power and efficiency. The work was achieved both numerically and experimentally. A summary of the finding from the work includes:

1) The angle of inclination, number of blades and length have the greatest effect on the power output and efficiency of a screw.

2) The inclination angle of a screw turbine did not have a large effect on how the screw fills, but will affect the output power and efficiency of a screw.

3) The power and torque are increased with an increase in the flow rate.

4) The maximum efficiency obtained from the results of the operation was $81.4 \%$ at $35^{\circ}$ inclination angle and a flow rate of $1.12 \mathrm{l} / \mathrm{s}$.

5) The maximum power of 9.03 watts was at $45^{\circ}$ inclination angle and a flow rate of $2.065 \mathrm{l} / \mathrm{s}$ and $72 \%$ efficiency.

6) Mechanical power is increased with an increase in the angle of inclination.

7) The torque increases with an increase of the length of the pitch and that means an increase in power.

\section{Conflicts of Interest}

The authors declare no conflicts of interest regarding the publication of this paper.

\section{References}

[1] Shahverdi, K., Loni, R., Ghobadian, B., Bellos, E., Gohari, S. and Marofi, S. (2019) Numerical Optimization Study of Archimedes Screw Turbine (AST): A Case Study. 
Renewable Energy, 145, 2130-2143. https://doi.org/10.1016/j.renene.2019.07.124

[2] Istepanian, H., Alwash, A., Tollast, R. and Al-Shibaany, Z.Y. (2018) Towards Sustainable Water Resources Management in Iraq. 1-45.

[3] Kumar, U., Singh, P. and Tiwari, A.C. (2016) Suitability of Archimedes Screws for Micro Hydro Power Generation in India. International Journal of Thermal Technologies, 6, 273-278. http://inpressco.com/category/ijtt/

[4] Raza, A., Mian, M.S. and Saleem, Y. (2013) Modeling of Archimedes Turbine for Low Head Hydro Power Plant in Simulink MATLAB. International Journal of Engineering Research \& Technology, 2, 2471-2477.

[5] Lyons, M. and Lubitz, W. (2013) Archimedes Screws for Microhydro Power Generation. Proceedings of the ASME 7 th International Conference on Energy Sustainability \& 11 th Fuel Cell Science, Engineering and Technology Conference, Minneapolis, 14-19 July 2013, V001T15A003. https://doi.org/10.1115/ES2013-18067

[6] Borah, S., Chowdhury, B., Gogoi, S. and Askary, Z. (2015) A Theoretical Study of Design Parameters of an Archimedean Screw Turbine. Journal of Material Science and Mechanical Engineering, 2, 32-34.

[7] Straalsund, J.L., Harding, S.F., Nuernbergk, D.M. and Rorres, C. (2018) Experimental Evaluation of Advanced Archimedes Hydrodynamic Screw Geometries. Journal of Hydraulic Engineering, 144, 1-10. https://doi.org/10.1061/(ASCE)HY.1943-7900.0001479

[8] Maulana, M.I., Syuhada, A. and Almas, F. (2018) Computational Fluid Dynamic Predictions on Effects of Screw Number on Performance of Single Blade Archimedes Screw Turbine. E3S Web of Conferences, EDP Sciences, Vol. 67, 10. https://doi.org/10.1051/e3sconf/20186704027

[9] Saroinsong, T., Soenoko, R., Wahyudi, S. and Sasongko, M.N. (2016) Performance of Three-Bladed Archimedes Screw Turbine. ARPN Journal of Engineering and Applied Sciences, 11, 9491-9495.

[10] Siswantaraa, A.I., Warjitoa, Budiarsoa, Harmadib, R., Syafei, M.H.G. and Adantaa, D. (2019) Investigation of the $a$ Angle's Effect on the Performance of an Archimedes Turbine. Energy Procedia, 156, 458-462. https://doi.org/10.1016/j.egypro.2018.11.084

[11] Müller, G. and Senior, J. (2009) Simplified Theory of Archimedean Screws. Journal of Hydraulic Research, 47, 666-669. https://doi.org/10.3826/jhr.2009.3475

[12] Dellinger, G., Garambois, P.-A., Dufresne, M., Terfous, A., Vazquez, J. and Ghenaim, A. (2016) Numerical and Experimental Study of an Archimedean Screw Generator. IOP Conference Series: Earth and Environmental Science, 49, Article ID: 102002. https://doi.org/10.1088/1755-1315/49/10/102002

[13] Saroinsong, T., Soenoko, R., Wahyudi, S. and Sasongko, M.N. (2016) Effect of Froude Number on Three-Bladed Archimedes Screw Turbine Efficiency. International Journal of Renewable Energy Research, 6, 1-6.

[14] Simmons, S. and Lubitz, W. (2017) Archimedes Screw Generators for Sustainable Energy Development. 2017 IEEE Canada International Humanitarian Technology Conference (IHTC), Toronto, 144-148.

[15] Maulana, M.I., Syuhada, A. and Nawawi, M. (2018) Blade Number Impact on Pressure and Performance of Archimedes Screw Turbine Using CFD. AIP Conference Proceedings, 1931, Article ID: 030037. https://doi.org/10.1063/1.5024096

[16] Khan, A., Khattak, A., Ulasyar, A., Imran, K. and Munir, M.A. (2019) Investigation of Archimedean Screw Turbine for Optimal Power Output by Varying Number of 
Blades. IEEE International Conference on Electrical, Communication, and Computer Engineering, Pakistan, 24-25 July2019, 1-6.

[17] Nuramal, A., Bismantolob, P., Date, A., Akbarzadeh, A., Mainil, A.K., Suryono, A.F. and Fiardia, E. (2017) Experimental Study of Screw Turbine Performance Based on Different Angle of Inclination. Energy Procedia, 110, 8-13.

https://doi.org/10.1016/j.egypro.2017.03.094

[18] Maulana, M.I., Syuhada, A. and Kurniawan, R. (2019) Experimental Study on the Effect of Flow Rate on the Performance of Two-Blade Archimedes Screw Turbine. Journal of Advanced Research in Fluid Mechanics and Thermal Sciences, 61, 10-19.

[19] Çengel, Y.A. and Cimbala, J.M. (2006) Fluid Mechanics: Fundamentals and Applications. Mc-Graw-Hill, New York.

[20] Holaman, J.P. and Gajda, W.J. (2001) Experimental Method for Engineers. McGrawHill, New York.

[21] Khalil, W.H., Obaid, Z.A.H. and Dawood, H.K. (2019) Exergy Analysis of Single-Flow Solar Air Collectors with Different Configurations of Absorber Plates. Heat Transfer-Asian Research, 48, 3600-3616. https://doi.org/10.1002/htj.21558

[22] Pritchard, P.J. (2011) Introduction to Fluid Mechanics. 8th Edition, Mc-Graw-Hill, Companies, New York.

[23] Sodja, J. (2007) Turbulence Models in CFD. University of Ljubljana. http://mafija.fmf.uni-lj.si/seminar/files/2006_2007/Turbulence_models_in_CFD.pdf

[24] Khalil, W.H. (2007) Modelling and Performance of a Wind Turbine. Anbar Journal of Engineering Sciences, 1, 116-127. 